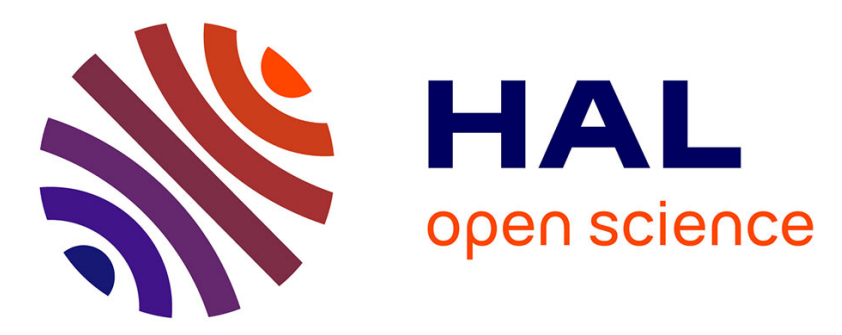

\title{
Active-Distributed Temperature Sensing to continuously quantify vertical flow in boreholes
}

T. Read, Olivier Bour, J. S. Selker, V. F. Bense, Tanguy Le Borgne, Rebecca

Hochreutener, Nicolas Lavenant

\section{- To cite this version:}

T. Read, Olivier Bour, J. S. Selker, V. F. Bense, Tanguy Le Borgne, et al.. Active-Distributed Temperature Sensing to continuously quantify vertical flow in boreholes. Water Resources Research, 2014, 50 (5), pp.3706-3713. 10.1002/2014WR015273 . insu-01005138

HAL Id: insu-01005138

https://hal-insu.archives-ouvertes.fr/insu-01005138

Submitted on 12 Jun 2014

HAL is a multi-disciplinary open access archive for the deposit and dissemination of scientific research documents, whether they are published or not. The documents may come from teaching and research institutions in France or abroad, or from public or private research centers.
L'archive ouverte pluridisciplinaire $\mathbf{H A L}$, est destinée au dépôt et à la diffusion de documents scientifiques de niveau recherche, publiés ou non, émanant des établissements d'enseignement et de recherche français ou étrangers, des laboratoires publics ou privés. 


\section{Water Resources Research}

\section{RESEARCH ARTICLE \\ 10.1002/2014WR015273 \\ Active-Distributed Temperature Sensing to continuously quantify vertical flow in boreholes}

Key Points:

- A prototype system monitored with DTS was deployed in a fractured rock aquifer

- The temperature of a heated FO cable is sensitive to vertical fluid velocities

- Empirical or an analytical relationship presented gives the flow velocity

Supporting Information:

- ReadMe File

- Figure S1-S2

- Figure captions S1-S2

Correspondence to:

T. Read,

tom.read@uea.ac.uk

Citation:

Read, T., O. Bour, J. S. Selker, V. F.

Bense, T. Borgne, R. Hochreutener, and N. Lavenant (2014), Active-Distributed Temperature Sensing to continuously quantify vertical flow in boreholes, Water Resour. Res., 50, 3706-3713, doi:10.1002/2014WR015273.

Received 13 JAN 2014 Accepted 15 APR 2014 Accepted article online 19 APR 2014 Published online 6 MAY 2014 elicited a $2.5^{\circ} \mathrm{C}$ cooling effect. It is envisaged that with further development this method will have applications where point measurements of borehole vertical flow do not fully capture combined spatiotemporal dynamics.

\section{Introduction}

\subsection{Flow Logging} through a magnetic field [Molz et al., 1994].

\author{
T. Read1, O. Bour2, J. S. Selker3, V. F. Bense1, T. Le Borgne'2, R. Hochreutener2,3, and N. Lavenant² \\ ${ }^{1}$ School of Environmental Sciences, University of East Anglia, Norwich, UK, ${ }^{2}$ Geosciences Rennes, CNRS, University of \\ Rennes 1, Rennes, France, ${ }^{3}$ Department of Biological and Ecological Engineering, Oregon State University, Corvallis, \\ Oregon, USA
}

Abstract We show how a distributed borehole flowmeter can be created from armored Fiber Optic cables with the Active-Distributed Temperature Sensing (A-DTS) method. The principle is that in a flowing fluid, the difference in temperature between a heated and unheated cable is a function of the fluid velocity. We outline the physical basis of the methodology and report on the deployment of a prototype A-DTS flowmeter in a fractured rock aquifer. With this design, an increase in flow velocity from 0.01 to $0.3 \mathrm{~m} \mathrm{~s}^{-1}$

Fluid flow logs in boreholes provide direct insight into the hydrogeological conditions encountered with depth in the subsurface. Such information provides not only a qualitative addition to other geophysical logs, but can classically be used to derive hydraulic property variations with depth during pumping tests [Molz et al., 1994; Paillet, 1998]. Various designs of flowmeter currently exist: impeller flowmeters [Molz et al., 1989]; heat pulse flowmeters which rely on the time taken for a packet of heated water to reach a thermistor [Hess, 1982]; and electromagnetic flowmeters which output the voltage generated as water moves

With the above mentioned methods, a flow log is obtained by continuously trolling a flowmeter down a borehole or by making stationary measurements at multiple depths. The use of traditional flowmeters can be time consuming where inversion methods used for aquifer characterization require many measurements in space, for example in multiple boreholes for flow tomography [Klepikova et al., 2013], or space and time, for example for fracture zone storage coefficient estimation [Paillet, 1998]. Furthermore, the physical presence of a flowmeter causes a resistance to flow in the borehole, potentially disturbing the fluid flow [Ruud et al., 1999]. We develop a new flow logging method based on Distributed Temperature Sensing (DTS) along Fiber Optic (FO) cables, a technology which gives spatially and temporally distributed measurements of temperature [Selker et al., 2006; Tyler et al., 2009]. With DTS, temperature measurements along a FO cable are derived from the return Stokes and anti-Stokes intensities; light at two predictable frequencies, backscattered from an initial laser pulse.

\subsection{Fiber-Optic Distributed Temperature Sensing}

DTS technology has found a wide range of applications in environmental monitoring [e.g., Selker et al., 2006]. In boreholes, where temperature-depth profiles usually change only very slowly with time, the main applications of DTS have so far been where the subsurface is thermally altered to give a transient thermal response. Example thermal alterations may be the result of fluid injections [Macfarlane et al., 2002; Leaf et al., 2012; Read et al., 2013], or heating cables [Freifeld et al., 2008]. While these methods are thermally active, in that the temperatures at depth have been intentionally altered with a view to observing a transient thermal response, the FO cable is at the same temperature as its immediate surroundings and the DTS method is essentially passive.

Alternatively, DTS can be deployed in an active mode, which we call Active-DTS (A-DTS). Here we define A-DTS as the distributed measurement of temperature along a FO cable with a distributed heat source 
incorporated into or in contact with the same cable, where the temperature data collected while actively heating are of primary interest. These temperature data reflect the combined efficiency of heat dissipation from the cable and the surrounding medium, so that spatially distributed estimates of the surrounding physical properties or fluid fluxes are possible. Temperature sensing FO cables are often ruggedized with steel armoring, allowing commonly available cables to be utilized for A-DTS by passing an electrical current through the metal cable materials. Example applications already exist in soil moisture studies. In an unsaturated porous medium, heat conduction from the heated cable depends on the moisture-dependent structure of soil water bridges between grains [Sayde et al., 2010; Striegl and Loheide, 2012], such that with A-DTS a distributed soil moisture sensor can be created.

A-DTS methods potentially can provide measurements of fluid fluxes in boreholes. Liu et al. [2013] showed that the temperature of a FO cable wrapped with a heating cable and deployed down hole is sensitive to horizontal groundwater flux through the surrounding porous medium. Here we propose a method based on A-DTS for the monitoring of vertical fluid velocity in boreholes. The general principle is that in steady state heat flow conditions, the temperature difference between a heated FO cable and adjacent unheated cable deployed down hole will be a function of the velocity of the fluid flowing parallel to the borehole axis. In this study, we first present an analytical relationship between fluid flow velocity and this quantity, $\Delta T$. Here we make the assumption that using a differential temperature accounts for any warming of the fluid due to the electrical heating or background fluid temperature differences caused by inflows to the borehole. We then present temperature data from a prototype A-DTS flowmeter deployed in a fractured rock aquifer, which we invert for the fluid velocity using the analytical result, conditioned in part from field data.

\section{Analytical Methods}

Prediction of the temperature measured on a heated FO cable requires consideration of both the cable construction and environmental setting. For example, Neilson et al. [2010] quantified the undesirable temperature increase on the surface of FO cables submerged in flowing rivers and heated by solar radiation. This analytic approach accounted for the fluid velocity-dependent heat transfer coefficient at the cable-fluid interface. In the borehole setting considered here, we adopt a similar approach, except that the heat input occurs in the cable center. We therefore also need to consider heat conduction through the cable materials if we are to reasonably predict the DTS measured temperature.

In our A-DTS flowmeter, we use a BruSens cable (Brugg cables, Switzerland), which consists of a stainless steel capillary tube, surrounded by braided stainless steel, held in a polyamide (PA) cladding (Figure 1a). The optical fibers, along which the temperature is measured, are located centrally in the capillary tube. This general construction is typical of many armored FO cables manufactured for temperature sensing applications [Tyler et al., 2009]. Connecting the steel armoring to a power supply generates a constant amount of heat per unit length. In steady state heat flow conditions, this amount of heat is transferred from the steel to the cladding, and then across the interface between the cladding and fluid.

In the heat transfer model, we consider steady state heat conduction through the cylindrical shell prescribed by the electrically insulating cladding of thickness $r_{2}-r_{1}$. We assume that the temperature gradient inside the steel is negligible, such that the temperature at the center of the cable is equivalent to the temperature at the steel-PA interface, $r_{1}$. If the heat transfer across the PA-fluid interface obeys Newton's Law of Cooling, then the diffusion equation in the cylinder can be solved to give:

$$
T_{1}-T_{\infty}=\Delta T=\frac{Q}{2 \pi}\left(\frac{1}{h r_{2}}+\frac{1}{k_{c}} \ln \frac{r_{2}}{r_{1}}\right)
$$

where $T_{1}$ is the temperature at $r_{1}, T_{\infty}$ is the temperature of the fluid beyond the thermal boundary layer, $Q\left(\mathrm{~W} \mathrm{~m}{ }^{-1}\right)$ is the heat input to the cable, $h\left(\mathrm{~W} \mathrm{~m}^{-2} \mathrm{~K}^{-1}\right)$ is the heat transfer coefficient, and $k_{c}\left(\mathrm{~W} \mathrm{~m}^{-1} \mathrm{~K}^{-1}\right)$ is the thermal conductivity of the material between $r_{1}$ and $r_{2}$. From inspection of equation (1), it can be seen that the value of $\Delta T$ can be increased by increasing $Q$, decreasing $k_{c}$, and decreasing $r_{1}$. The effect of increasing $r_{2}$ has two opposing effects; a greater surface area for heat exchange decreases $\Delta T$, while the resulting higher thermal resistance thus increases $\Delta T$. 


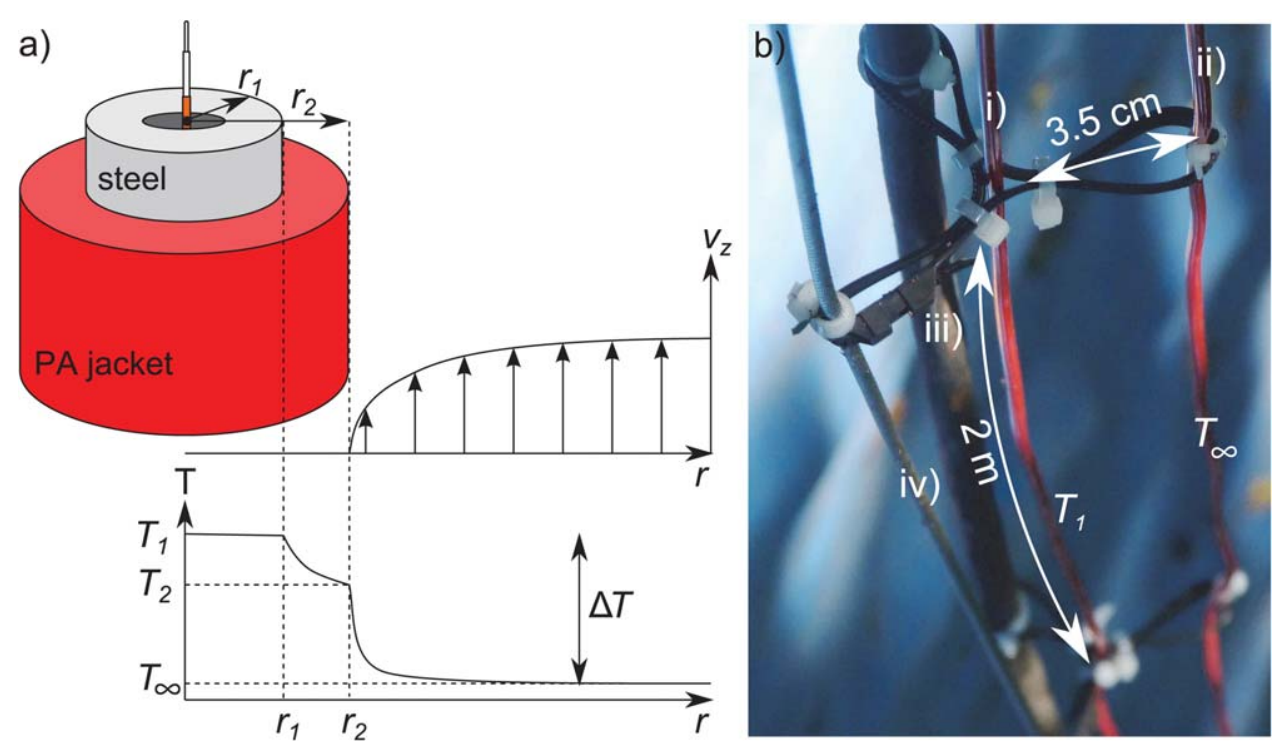

Figure 1. (a) Schematic of the heated FO-cable with idealized fluid velocity and temperature profiles radially from the center of the cable when the cable is electrically heated. (b) Section of the A-DTS tool with (i) centrally held heated FO-cable, (ii) reference FO-cable, (iii) power supply cable, and (iv) steel rope.

The heat transfer coefficient is a function of the thermal conductivity of the fluid, the Nusselt number, and the characteristic length:

$$
h=\frac{k_{f}}{L} N u,
$$

where $k_{f}$ is the thermal conductivity of the fluid, $L[\mathrm{~m}]$ is the characteristic length (here we use $0.11 \mathrm{~m}$, the diameter of the borehole). At low flow velocities, heat transfer by free convection, driven by buoyant forces, becomes significant. Therefore, in the present case $\mathrm{Nu}$ is the Nusselt number for combined forced $\left(N u_{F}\right)$ and free (natural) convection $\left(N u_{N}\right)$. This combined Nusselt number is given by [Incropera et al., 2007]:

$$
N u=\left(N u_{F}^{n} \pm N u_{N}^{n}\right)^{\frac{1}{n}}
$$

where $n$ typically ranges from 3 to 4 . For a vertically orientated surface, $n$ is usually taken as 3 . The plus or minus sign in equation (3) depends on whether the buoyant fluid motion assists or opposes the fluid flow, thus either enhancing or reducing the efficiency of heat transfer. In the following interpretation of the field trial, we assume that all of the flow is upward (as would be expected to be the case while pumping from the top of the borehole), allowing the addition form of this equation to be used. The Nusselt number approximation for forced convection due to fluid flow is based on laminar flow over a flat isothermal plate, and is given by [Incropera et al., 2007]:

$$
N u_{F}=0.664 \operatorname{Re}^{\frac{1}{2}} \operatorname{Pr}^{\frac{1}{3}}
$$

where Pr is the Prandtl number, and Re, the Reynolds number, is calculated for the characteristic length $L$. Many relationships exist for free convection Nusselt number approximations over a range of geometries [e.g., Churchill and Chu, 1975]. Due to the sensitivity of $\Delta T$ to the value of $N u_{N}$, in the following, $N u_{N}$ is treated as an unknown and used to fit the model to observed $\Delta T$ values.

\section{Site Description}

The field site at Stang-er-Brune, Brittany, France, was chosen to test the A-DTS method as a large amount of hydrogeophysical data for the site already exist [De Dreuzy et al., 2006; Bour et al., 2013]. Four boreholes up 
to $100 \mathrm{~m}$ deep and shallower piezometers in close proximity are accessible in a fractured granite and micaschist. Previous field campaigns have identified the most transmissive fractures intersecting the boreholes and interborehole connectivity [Le Borgne et al., 2007], and flow routes through the fracture network [Dorn et al., 2012]. Hydraulic heads at the site generally increase with depth and drive a mainly upward vertical flow in the boreholes in ambient conditions. To test the prototype system, borehole B2 was used. This borehole is cased from the surface to $24.8 \mathrm{~m}$ and then open to a depth of $100 \mathrm{~m}$. The cased section has a larger diameter $(12.8 \mathrm{~cm})$ than the open hole $(10.4-10.9 \mathrm{~cm})$. When pumped, flow to the borehole originates from fractures at depths of 27.9, 55.6, 58.9, 79.9, and $98.0 \mathrm{~m}$ [Le Borgne et al., 2007].

\section{Field Methods}

We constructed the prototype A-DTS flowmeter from a single $295 \mathrm{~m}$ length of BruSens FO cable. Of this, 78 $\mathrm{m}$ could be heated by connecting this electrically isolated section to a power supply. During the experiments, the heated cable was powered by 220 and 233 ACV, giving power intensities along the cable of 18.8 and $21.8 \mathrm{~W} \mathrm{~m}^{-1}$, respectively. An equal length of unheated cable, obtained by bending the cable back on itself after the latter electrical connection, was held at a uniform distance away of $3.5 \mathrm{~cm}$ using cable ties every $2 \mathrm{~m}$ (Figure 1b). From DTS temperature measurements along these two parallel lengths of heated and unheated cable, the heating effect $\Delta T$ can be obtained. A power supply cable and a steel cable to support the weight of the system were also fixed relative to the central heated cable using cable ties. These cable tie centralizers also helped to ensure that the heated cable remained away from the borehole wall. The flowmeter was then installed in B2 to monitor the borehole vertical flow at all depths simultaneously.

For the DTS calibration, additional lengths of unheated cable at the surface were placed in ambient (water kept mixed with an air pump) and a cold calibration bath (water wetted ice in an insulated box). Because the tool was constructed from a single length of cable containing two fibers, spliced together at the far end, the resulting duplexed DTS data set contained four reference sections. In each bath a Tinytag logger (Gemini Data Loggers, UK), independently recorded the temperature. The Stokes and anti-Stokes backscatter intensities were obtained every $12.5 \mathrm{~cm}$ along the cable using a Silixa Ultima instrument with $5 \mathrm{~km}$ range. The instrument integrated the backscatter over times ranging from 1 to $10 \mathrm{~s}$. The data were subsequently postprocessed to derive the temperature using the Stokes and anti-Stokes intensities from three of the reference sections and the single-ended algorithm outlined in Hausner et al. [2011].

To test the response of the A-DTS system to a range of flow velocities, we pumped the borehole from a depth of around $10 \mathrm{~m}$ at rates ranging from 5.2 to $181 \mathrm{~L} \mathrm{~min}^{-1}$, generating upflow throughout the borehole. The $\Delta T$ response and relationship to flow, as reported in the following, corresponds to a $2 \mathrm{~m}$ spatially averaged value between depths of 25.4 and $27.4 \mathrm{~m}$. This section is in the open borehole above all known inflow zones and is referred to as the test section.

\section{Results and Discussion}

To give an indication of the responsiveness of the A-DTS system, Figure 2 shows a spatially averaged time series of the heated cable and reference cable temperature over the test section. Upon heating, the A-DTS system responded very rapidly, with the heated cable increasing in temperature by almost $10^{\circ} \mathrm{C}$. Within $15 \mathrm{~s}, 90 \%$ of this temperature plateau was achieved. Over the time frame shown, the reference cable does not experience any warming, suggesting that it is located far enough away to be out of the thermal boundary layer.

The relationship between $\Delta T$ and the fluid velocity in the test section is shown in Figure 3. The $\Delta T$ values shown here are after further spatial filtering for reasons outlined in the following. Over a velocity range from 0.01 to $0.33 \mathrm{~m} \mathrm{~s}^{-1}$, a $2.5^{\circ} \mathrm{C}$ range in $\Delta T$ is obtained. The analytical solution, optimized to $N u_{N}=80$ and 86 for the heating rates of 18.8 and $21.8 \mathrm{~W} \mathrm{~m}^{-1}$, respectively, suggests a diminishing sensitivity to fluid velocity toward low and high flow extremes. The lower limit to the sensitivity occurs as heat transfer to the fluid by free convection begins to dominate over forced convection. The upper limit to the flow sensitivity is the result of the thermal boundary layer reducing to a minimum. The A-DTS system as deployed here in this configuration, seems to be most suited to measuring midrange velocities that typically would be measured with an electromagnetic or impeller flowmeter. 


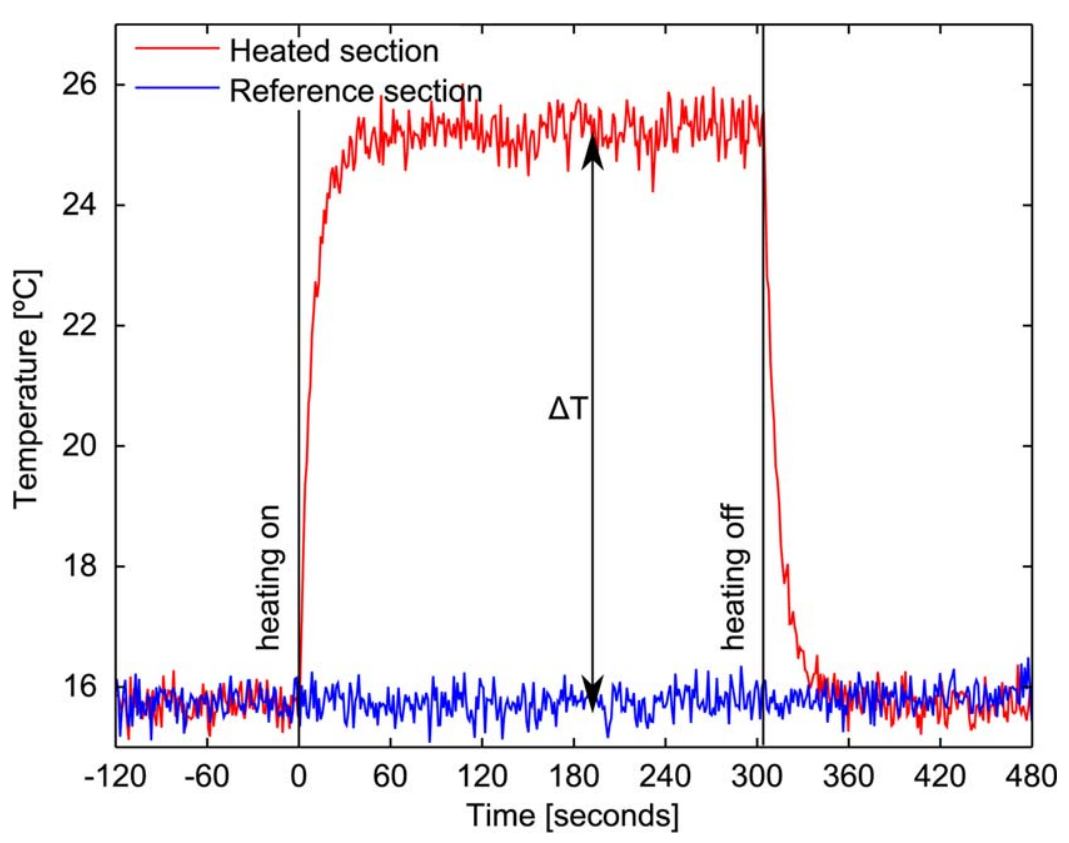

Figure 2. Spatially averaged temperature on the heated and reference cable over the test section (25.4-27.4 m), while pumping at $14.7 \mathrm{~L} \mathrm{~min}^{-1}$.

A 5 min average of the entire heated section and reference section temperature while pumping at $180 \mathrm{~L} \mathrm{~min}^{-1}$ are shown in Figure 4a. The effect of the $2 \mathrm{~m}$ spaced centralizers is to locally reduce the heated cable temperature. We hypothesize that this is due to the development of more energetic turbulent flow as the water moves through the centralizer structure, enhancing the heat exchange between fluid and cable. For the borehole geometry and velocities we have here, the Reynolds number is up to $6 \times 10^{3}$, thus turbulence may be readily stimulated downstream of any obstructions. We do not account for this in the analytical model, and a full analysis of this would need a simulation of the applicable equations for turbulent flow within the flow geometry here. For the $\Delta T$-flow calibration, the temperature data from the heated cable were first filtered to remove these artifacts introduced by the centralizers so that the analytical solution could be used with realistic parameters (bold line in Figure 4a). The cold spots in the heated cable profile were removed by applying a moving median filter to select the upper $25 \%$ of temperature data within a $2 \mathrm{~m}$ window. We assume that this results in heated cable temperatures that are unaffected by the centralizers, therefore, the $\Delta T$-flow calibration can only be expected to provide reasonable velocity estimates either for the filtered data, or the unfiltered data away from the centralizers. It should however be noted that the removal of these artifacts is not essential as the flowmeter could be entirely empirically calibrated. The reference cable data were also processed but with a simple $2 \mathrm{~m}$ moving average.

The velocity profile for a pumping rate of $180 \mathrm{~L} \mathrm{~min}^{-1}$, calculated from $\Delta T$ (Figure $4 \mathrm{~b}$ ), using equations (1)-(4) and the parameters in Table 1 is shown in Figure 4c. In addition, flow velocities measured with an impeller flowmeter $(\mathrm{H}+$ Network, www.hplus.ore.fr), are also plotted. These data were obtained at a lower pumping rate of $42 \mathrm{~L} \mathrm{~min}^{-1}$ in July 2012. Despite this, the velocity profile should at least provide a qualitative comparison, since due to variations in the hydraulic conditions of each fracture, it cannot be expected to be entirely constant through time or scale exactly with the pumping rate [Paillet, 1998]. The profile of $\Delta T$ measured with the A-DTS flowmeter is clearly anticorrelated with the impeller measured fluid velocity, with the resulting flow log showing similar step changes in velocity arising from discrete fracture zone inflows.

Additionally, there are both some anomalously high and low values of $\Delta T$ that translate into anomalously low and high velocities, respectively, that cannot easily be explained just by considering vertical flow up the borehole. The high value of $\Delta T$ centered at around $60 \mathrm{~m}$ was present at all pumping rates and is thought to be due to the heated cable touching the borehole wall. This is likely to be an issue in most deployments of the system where there is any deviation in the borehole but is something we envisage can be minimized with alternative designs. The low value of $\Delta T$ at around $79 \mathrm{~m}$ appears to correspond to the fracture at this 


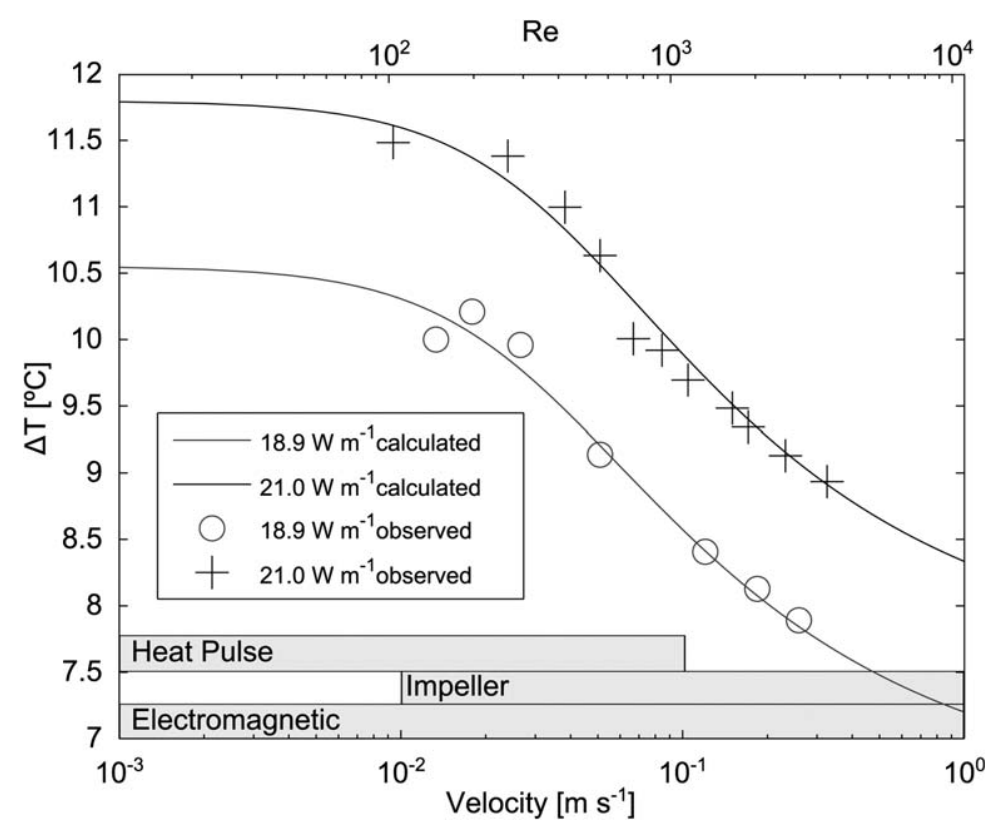

Figure 3. Observed $\Delta T$ based on the filtered data and computed $\Delta T$ relationship with fluid velocity for power inputs of 18.9 and $21.0 \mathrm{~W} \mathrm{~m}^{-1}$, with typical sensitivity ranges of heat pulse, impeller, and electromagnetic flowmeters.

depth. Inflowing fractures generate nonaxial velocity components and even turbulence, that could locally increase heat dissipation from the heated cable. However, it may be difficult to quantitatively relate this $\Delta T$ value to fracture zone inflows due to the complexity of such regions and limited spatial resolution of

a)

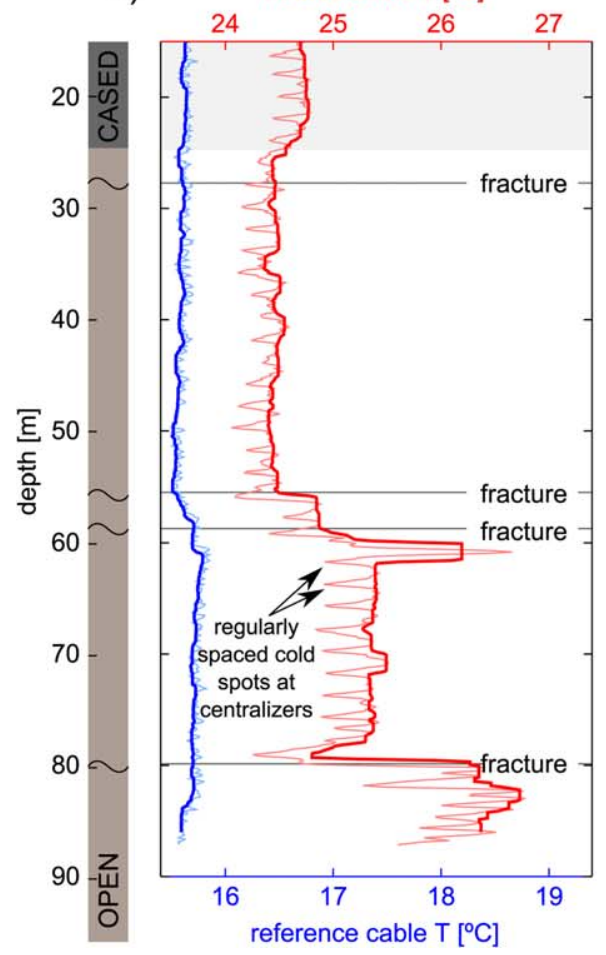

b)

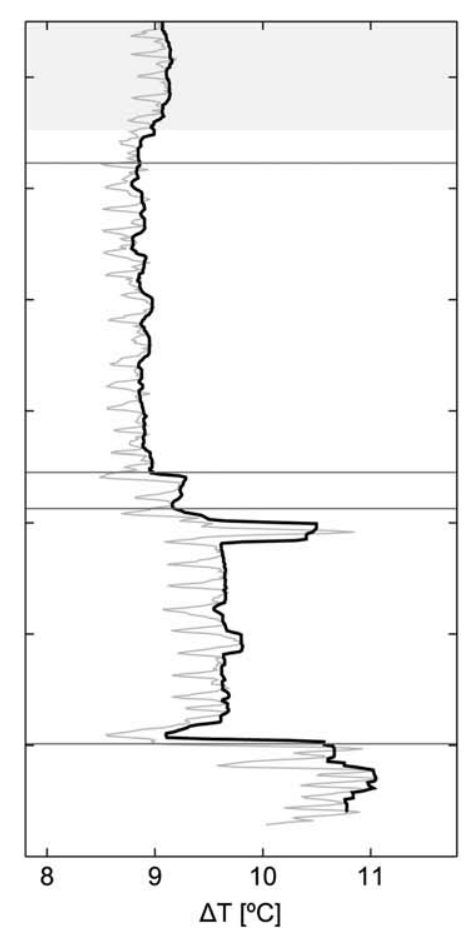

c)

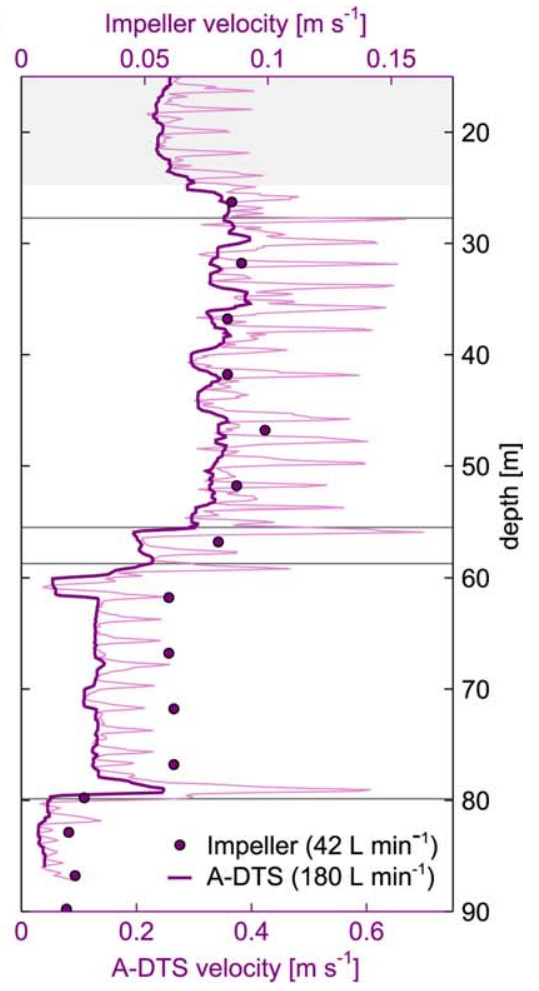

Figure 4. (a) Reference cable and heated cable temperatures while pumping from $7 \mathrm{~m}$ depth at $180 \mathrm{~L} \mathrm{~min}^{-1}$ (pale lines are temporally averaged, bold lines temporally averaged with additional spatial filtering). (b) Corresponding $\Delta T$ profile (the light line is the difference between the purely temporally averaged data, and the bold line is the difference between the

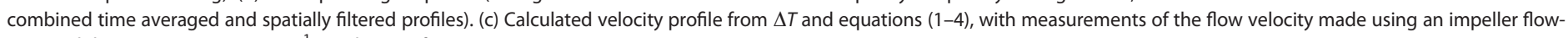
meter while pumping at $42 \mathrm{~L} \mathrm{~min}^{-1}$ in July 2012 for comparison. 
Table 1. BruSens FO Cable and Water Physical and Thermal Properties Used in the Analytical Solution

BruSens Cable Water

Units

Diameter of steel core

Cable diameter

Thermal conductivity

Density

0.00226

0.00385

0.245

Water

Dynamic viscosity

2.41

0.598

1.00

$1.00 \mathrm{E}-03$

1.00 E-06
$W \mathrm{~m}^{-1} \mathrm{~K}^{-1}$

$\mathrm{g} \mathrm{cm}^{-3}$

$\mathrm{N} \mathrm{s} \mathrm{m}^{-2}$

$\mathrm{m}^{2} \mathrm{~s}^{-1}$

standard DTS installations. Similar problems at discrete inflow zones are nevertheless also encountered with other flow logging methods.

A key issue in the future designs of A-DTS flowmeters is the centralizing mechanism. Where the cable touches the borehole wall, as would commonly happen in boreholes with any deviation, we have seen that this causes major temperature artifacts. The centralizers used in this study were designed to minimize this but they too give temperature artifacts of their own, which in this set up were readily identified due to their regular spacing. This effectively limited the spatial resolution of the flowmeter to detect changes in the fluid velocity to around $2 \mathrm{~m}$, which is significantly poorer than the spatial resolution possible with the DTS deployed $(0.29 \mathrm{~m})$. A further unexpected outcome was that at the centralizer locations, $\Delta T$ had an enhanced sensitivity to flow at low velocities (see supporting information). This raises the possibility that future designs could include a denser centralizing system that uniformly disturbs the flow, and is optimized to provide maximum sensitivity over a given velocity range. This would give a spatial resolution for fluid flow logging similar to the spatial resolution of the DTS instrument. While it would be more difficult to forward model the temperature response of the A-DTS flowmeter, one could readily build up an empirical calibration between $\Delta T$ and flow velocity in the field as we also did here.

Additional work needs to be carried out to assess the significance of the flow direction on the $\Delta T$ response. Equation (3) suggests that at least at low flow velocities, two different $\Delta T$ responses may result depending on whether the fluid flow is acting in the same direction or opposing buoyancy driven flow. This need not be a prohibitive issue as the flow direction can be found from the gradient of the change in reference cable temperature relative to preheating. While Figure 2 shows that over a short time scale the warming of the fluid is negligible, after carrying out multiple simultaneous heating experiments, we observed that the reference cable temperature had increased. A similar effect can be seen in the recent work of Banks et al. [2014], where in the example from the Willunga field site the sign of the gradient of the fluid temperature profiles indicates that the flow direction is upward to the pump. This effect is apparent because the water just before it reaches the pump has a longer mean residence time and has therefore experienced more heating than water which has only just entered the borehole. So using the method proposed here, if in fact two $\Delta T$ flow calibrations exist, then the appropriate calibration for flow can be chosen. This is something that we did not fully explore in this set of field experiments, but could be tested on a smaller scale with a laboratory setup.

\section{Conclusions}

We have shown that A-DTS is a feasible approach for monitoring spatially and temporally changing borehole vertical flows. The difference in temperature between an electrically heated fiber optic cable and a passive, nonheated reference cable can be related to vertical fluid velocities. With FO cables of small thermal inertia, as used here, the thermal time constant of the cable is likely to be much smaller than the time constant of the borehole when hydraulically stressed. Therefore, the A-DTS method is likely to find applications where it is necessary to monitor temporal changes in fluid flow. The general advantages of using DTS that have been found in other disciplines similarly apply here for fluid flow measurements with A-DTS. With an A-DTS flowmeter constructed from a single FO cable, full spatiotemporal coverage of flow measurements could be achieved simultaneously in multiple boreholes at a site. While we have shown here that in general the method shows great promise for fluid flow logging, future work is needed to address the issues related to field deployment, and to determine how to optimize the sensitivity for the desired application. 


\section{Acknowledgments}

Funding for this work was provided by the INTERREG IV project CLIMAWAT, the national network of hydrogeological sites $\mathrm{H}+$, the ANR project CRITEX ANR-11-EQPX-0011, and a Natural Environment Research Council (NERC) studentship (NE/ J500069/1) to Tom Read. Part of the support for the participation of John Selker and provision of some of the fiber optic cables were provided by the Center for Transformative Environmental Monitoring Programs (CTEMPs) funded by the National Science Foundation. The data collected for this study will be available from the national network of hydrogeological sites $\mathrm{H}+$, at http:// hplus.ore.fr/en/. We thank the two anonymous reviewers and Editor for their constructive comments on the manuscript.

\section{References}

Banks, E. W., M. A. Shanafield, and P. G. Cook (2014), Induced temperature gradients to examine groundwater flowpaths in open boreholes, Ground Water. [Available at http://onlinelibrary.wiley.com/doi/10.1111/gwat.12157/full].

Bour, O., T. Le Borgne, N. Lavenant, T. Labasque, L. Longuevergne, L. Aquilana, R. Hochreutener, J. Jiminez-Martinez, and P. Davy (2013), The hydrogeological observatory of ploemeur (France): Long-term monitoring and experimentations, in Abstracts With Programs, 45(7), 510, Geol. Soc. of Am.

Churchill, S. W., and H. Chu (1975), Correlating equations for laminar and turbulent free convection from a vertical plate, Int. J. Heat Mass Transfer, 18, 1323-1329.

De Dreuzy, J.-R., J. Bodin, H. Le Grand, P. Davy, D. Boulanger, A. Battais, O. Bour, P. Gouze, and G. Porel (2006), General database for ground water site information, Ground Water, 44(5), 743-748, doi:10.1111/j.1745-6584.2006.00220.x.

Dorn, C., N. Linde, T. L. Borgne, O. Bour, and M. Klepikova (2012), Inferring transport characteristics in a fractured rock aquifer by combining single-hole ground-penetrating radar reflection monitoring and tracer test data, Water Resour. Res., 48, W11521, doi:10.1029/ 2011 WR011739.

Freifeld, B. M., S. Finsterle, T. C. Onstott, P. Toole, and L. M. Pratt (2008), Ground surface temperature reconstructions: Using in situ estimates for thermal conductivity acquired with a fiber-optic distributed thermal perturbation sensor, Geophys. Res. Lett., 35, L14309, doi: $10.1029 / 2008$ GL034762.

Hausner, M. B., F. Suárez, K. E. Glander, N. V. D. Giesen, J. S. Selker, and S. W. Tyler (2011), Calibrating single-ended fiber-optic raman spectra distributed temperature sensing data, Sensors, 11, 10,859-10,879, doi:10.3390/s111110859.

Hess, A. E. (1982), A heat-pulse flowmeter for measuring low velocities in boreholes, Open File Rep., 82-699, U.S. Geol. Surv., Denver.

Incropera, F. P., D. Dewitt, T. Bergman, and A. Lavine (2007), Fundamentals of Heat and Mass Transfer, John Wiley, New York.

Klepikova, M. V., T. Le Borgne., O. Bour, and J.-R. de Dreuzy (2013), Inverse modeling of flow tomography experiments in fractured media, Water Resour. Res., 49, 7255-7265, doi:10.1002/2013WR013722.

Le Borgne, T., et al. (2007), Comparison of alternative methodologies for identifying and characterizing preferential flow paths in heterogeneous aquifers, J. Hydrol., 345(3-4), 134-148, doi:10.1016/j.jhydrol.2007.07.007.

Leaf, A. T., D. J. Hart, and J. M. Bahr (2012), Active thermal tracer tests for improved hydrostratigraphic characterization, Ground Water, 50(5), 726-735, doi:10.1111/j.1745-6584.2012.00913.x.

Liu, G., S. Knobbe, and J. Butler (2013), Resolving centimeter-scale flows in aquifers and their hydrostratigraphic controls, Geophys. Res. Lett., 40, 1098-1103, doi:10.1002/grl.50282.

Macfarlane, A., A. Förster, D. Merriam, J. Schrötter, and J. Healey (2002), Monitoring artificially stimulated fluid movement in the Cretaceous Dakota aquifer, western Kansas, Hydrogeol. J., 10(6), 662-673, doi:10.1007/s10040-002-0223-7.

Molz, F., R. Morin, A. Hess, J. Melville, and O. Given (1989), The impeller meter for measuring aquifer permeability variations: Evaluations and comparison with other tests, Water Resour. Res., 25, 1677-1683.

Molz, F., G. Boman, S. Young, and W. Waldrop (1994), Borehole flowmeters: Field application and data analysis, J. Hydrol., 163(3-4), 347371, doi:10.1016/0022-1694(94)90148-1.

Neilson, B. T., C. E. Hatch, H. Ban, and S. W. Tyler (2010), Solar radiative heating of fiber-optic cables used to monitor temperatures in water, Water Resour. Res., 46, W08540, doi:10.1029/2009WR008354.

Paillet, F. L. (1998), Flow modeling and permeability estimation using borehole flow logs in heterogeneous fractured formations, Water Resour. Res., 34, 997-1010, doi:10.1029/98WR00268.

Read, T., O. Bour, V. Bense, T. Le Borgne, P. Goderniaux, M. Klepikova, R. Hochreutener, N. Lavenant, and V. Boschero (2013), Characterizing groundwater flow and heat transport in fractured rock using fiber-optic distributed temperature sensing, Geophys. Res. Lett., 40, 20552059, doi:10.1002/grl.50397.

Ruud, N., Z. Kabala, and F. Molz (1999), Evaluation of flowmeter-head loss effects in the flowmeter test, J. Hydrol., 224(1), 55-63.

Sayde, C., C. Gregory, M. Gil-Rodriguez, N. Tufillaro, S. Tyler, N. van de Giesen, M. English, R. Cuenca, and J. S. Selker (2010), Feasibility of soil moisture monitoring with heated fiber optics, Water Resour. Res., 46, W06201, doi:10.1029/2009WR007846.

Selker, J. S., et al. (2006), Distributed fiber-optic temperature sensing for hydrologic systems, Water Resour. Res., 42, W12202, doi:10.1029/ 2006 WR005326.

Striegl, A. M., and S. P. I. Loheide (2012), Heated distributed temperature sensing for field scale soil moisture monitoring, Ground Water, 50(3), 340-347, doi:10.1111/j.1745-6584.2012.00928.x.

Tyler, S. W., J. S. Selker, M. B. Hausner, C. E. Hatch, T. Torgersen, C. E. Thodal, and S. G. Schladow (2009), Environmental temperature sensing using Raman spectra DTS fiber-optic methods, Water Resour. Res., 45, W00D23, doi:10.1029/2008WR007052. 